\title{
Agricultura urbana: desenvolvimento de um protótipo para o cultivo de hortaliças em ambiente residencial
}

\begin{abstract}
O desenvolvimento de tecnologias e processos para a produção de alimentos em residências e na área urbana, tem sido uma tendência emergente nas áreas metropolitanas. O objetivo do presente trabalho foi o desenvolvimento e teste de um protótipo para o cultivo de hortaliças em ambiente residencial, para promover a segurança alimentar no meio urbano. Esse protótipo foi baseado nos princípios de um lisímetro de nível freático constante, pois permitiria um fluxo contínuo de água para a cultura pelo princípio da capilaridade, não demandava energia, e foi construído com materiais disponíveis para comercialização no meio urbano, como tubos, acessórios e conexões de PVC, e reservatórios de plástico. A instalação e testes hidráulicos do lisímetro foram realizados em uma residência na cidade de Sorocaba, reproduzindo as condições para a finalidade de produção residencial de alimentos. Após a construção e teste hidráulico, procedeu-se ao plantio da salsa (Petroselinum crispum). Três plantios foram realizados para se determinar a melhor profundidade do lençol freático, a qual foi de $0,20 \mathrm{~m}$. Posteriormente, procedeu-se ao plantio do espinafre (Tetragonia expansa). Nesse experimento, além da matéria seca na época da colheita, foi levantada a cobertura vegetal e a altura do espinafre, ao longo do ciclo. As condições de umidade do solo permitiram um crescimento potencial da cultura, como pôde ser constatado por meio da avaliação visual e fotográfica da planta colhida, além dos dados de altura da planta, a qual atingiu $21 \mathrm{~cm}$. Na colheita, a produtividade alcançou 1.265,1 kg.ha-1, considerando a matéria seca. Ao longo do ciclo da cultura do espinafre, o consumo de água foi monitorado e atingiu 74 mm correspondendo a uma eficiência do uso da água de 0,25 kg.m-3, ou 17,10 t.ha-1.mm-1. A simplicidade construtiva e operacional, além da independência do suprimento de energia, demonstrou que o sistema foi adequado para o uso em residências, contribuindo para o planejamento do uso de recursos naturais voltados a promover a soberania e segurança alimentar no meio urbano.
\end{abstract}

Palavras-chave: Lisímetros; Eficiência do uso da água; Espinafre.

\section{Urban agriculture: development of a prototype for growing vegetables in residential environment}

\begin{abstract}
The development of new technologies for food production in home and urban areas has become a growing trend in metropolitan areas. The main goal of this research was to develop and test a prototype for vegetables cultivation in residential areas to promote food safety in urban areas. This prototype is based on a constant water level lysimeter principle and built with materials available in urban areas like tubes, accessories, PVC connections and plastic container. The installation and hydraulic test of the lysimeter were made in a residence in Sorocaba city in order to verify the handling obstacles by the residences. After the construction and hydraulic test the lysimeter was filled with vegetal soil and then the parsley (Petroselinum crispum) planting. Three plantings were carried out to determine the best depth of the water table, which was $0.20 \mathrm{~m}$. Subsequently, spinach (Tetragonia expansa) was planted. In this experiment, in addition to the dry matter at harvest time, the vegetable cover and the height of the spinach were raised throughout the cycle. The soil moisture conditions allowed for a potential growth of the crop, as could be seen through the visual and photographic evaluation of the harvested plant, in addition to the plant height data, which reached 21 $\mathrm{cm}$. At harvest, productivity reached 1,265.1 kg.ha-1, considering dry matter. Throughout the spinach culture cycle, water consumption was monitored and reached $74 \mathrm{~mm}$, corresponding to a water use efficiency of $0.25 \mathrm{~kg} \cdot \mathrm{m}-3$, or $17.10 \mathrm{t}$.ha-1. mm-1. The constructive and operational simplicity, in addition to the independence of the energy supply, demonstrated that the system was suitable for use in homes, contributing to the planning of the use of natural resources aimed at promoting sovereignty and food security in the urban environment.
\end{abstract}

Keywords: Lysimeters; Water use efficiency; Spinach.

Topic: Planejamento, Gestão e Políticas Públicas Ambientais

Reviewed anonymously in the process of blind peer

Gerson Araujo de Medeiros (iD

Universidade Estadual Paulista Júlio de Mesquita Filho, Brasil http://orcid.org/0000-0002-9122-3909

gerson.medeiros@unesp.br

Kariny Kimiko Diz Furuta (DD

Universidade Estadual Paulista Júlio de Mesquita Filho, Brasil

http://orcid.org/0000-0002-0172-8066

karinykdf@gmail.com

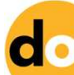

DOI: 10.6008/CBPC2179-6858.2021.003.0052
Received: 03/03/2021

Approved: 25/03/2021
Referencing this:

MEDEIROS, G. A.; FURUTA, K. K. D.. Agricultura urbana: desenvolvimento de um protótipo para o cultivo de hortaliças em ambiente residencial. Revista Ibero Americana de Ciências Ambientais, v.12, n.3, p.651-663, 2021. DOI: http://doi.org/10.6008/CBPC2179-6858.2021.003.0052 


\section{INTRODUÇÃO}

No Brasil, historicamente o crescimento urbano tem sido associado com a industrialização e o êxodo rural, potencializado a partir dos anos 1950, além de uma mudança do perfil da produção agrícola, que passa de subsistência para exportação (ANDRADE et al., 2001). Em 1950, a população brasileira era cerca de 52 milhões de habitantes e, desse total, cerca de 18 milhões, ou 35\%, viviam em áreas urbanas. Nas estimativas oficiais mais recentes, em 2010, a população brasileira alcançou 190 milhões de habitantes, dos quais $84 \%$, ou cerca de 160 milhões de pessoas, estavam distribuídas nas cidades. Essa rápida expansão urbana pode levar ao aumento da insegurança alimentar e redução na taxa média de autossuficiência de grãos, pela ocupação das áreas de produção de alimentos, como tem sido observado na China (HE et al., 2017). Nesse contexto, emerge a necessidade de novos paradigmas de gestão do espaço urbano que engloba alternativas sustentáveis para a população, e atendendo às suas diferentes especificidades, como o abastecimento de alimentos.

A cadeia produtiva de alimentos está associada a uma diversidade de categorias de impactos ambientais de repercussão para a sociedade contemporânea, como as mudanças climáticas, o uso da água, emissões tóxicas e mudanças no habitat (COSTA et al., 2018; MARQUES et al., 2020). Com a urbanização, tais impactos tendem a ser potencializados pela perda de terras agrícolas periurbanas, além do aumento da dependência de sistemas agrícolas distantes, levando ao incremento das emissões de gases de efeito estufa associadas ao transporte e armazenamento (ULM et al., 2019).

$\mathrm{Na}$ Europa, os alimentos provaram ser a categoria de consumo com os maiores impactos ambientais incorporados e para a qual as perdas e desperdícios de alimentos, em toda a cadeia de abastecimento, são os principais responsáveis (EEA, 2018). Nesse continente, a preocupação com as mudanças climáticas associada com a vulnerabilidade na segurança alimentar levou a um crescente interesse na produção agrícola urbana (HALL et al., 2014)

O conceito "Agricultura urbana" está relacionado a toda atividade agrícola situada no interior e entorno das cidades (áreas periurbanas), podendo ainda ser de uso coletivo ou individual, mesmo que em áreas públicas (parques, praças, canteiros e terrenos baldios) (ULM et al., 2019). Ela se difere da agricultura tradicional por permitir a sua implantação em praticamente qualquer local, em espaços abertos ou fechados, como o interior de uma residência

Trata-se de uma prática que se relaciona com a produção alimentícia, conservação de recursos naturais, melhor aproveitamento de um espaço, redução do impacto ambiental resultante do uso antrópico, manejo do solo e da água (BENIS et al., 2017). No tocante à alimentação e à saúde, a agricultura urbana tem a função de contribuir com os sistemas urbanos de produção alimentar, promovendo e fortalecendo a segurança alimentar e nutricional (RIBEIRO et al., 2015).

Apesar de ser um tema em ascensão, sua origem é de meados da década de 1970, quando a sociedade começou a perceber os riscos indiretos que a globalização produziria a longo prazo (DEELSTRA et al., 2000). A literatura apresenta relatos de agricultura urbana em uma diversidade de países, como México 
(DIELEMAN, 2017), Colômbia (FEOLA et al., 2019), Holanda (WIELEMAKER et al., 2019) e Gana (BOLANG et al., 2019) dentre outros.

No Brasil, a agricultura urbana está inserida nos princípios do Programa de Agricultura Urbana e Periurbana desenvolvido pelo Ministério do Desenvolvimento Social e Combate à Fome (BRANCO et al., 2011). Exemplos de produção de alimentos ou de espécies vegetais no meio urbano, têm sido relatados em regiões metropolitanas do Brasil, como Belém, no estado do Pará (MADALENO, 2000); São Luís, no estado do Maranhão (MADALENO, 2011); Recife, no estado de Pernambuco (CARVALHO et al., 2017); e São Paulo, no estado de São Paulo (RIBEIRO et al., 2015). Todavia, esses relatos se restringem à produção agrícola em estufas comerciais ou espaços abertos urbanos, sendo dada pouca atenção ao cultivo residencial.

Portanto, se emerge a necessidade do desenvolvimento de técnicas e tecnologias para apoiar a agricultura urbana, notadamente na área residencial, incorporando princípios da sustentabilidade, como o uso eficiente dos recursos naturais, a soberania e a segurança alimentar. Nesse aspecto, tecnologias como os lisímetros têm potencial de aplicação no ambiente residencial, por envolverem princípios condizentes com a sustentabilidade da produção de alimentos.

Os lisímetros têm sido utilizados para diferentes aplicações pela possibilidade do controle do fluxo de água e matéria, destacando-se o balanço hídrico de culturas irrigadas (MEDEIROS et al., 2001; MEDEIROS et al., 2005), a evaporação do solo (MEDEIROS et al., 1998), a percolação de nutrientes e poluentes no perfil do solo (ALBERS et al., 2020). Existem diferentes tipos de lisímetros que podem ser adaptados para as mais diversas condições do plantio, clima, disponibilidade de materiais e custos envolvidos em sua construção (ABOUKHALED et al., 1982).

Um desses tipos, conhecido como lisímetro de lençol freático de nível constante, se destaca pelo custo e facilidade operacional (ABOUKHALED et al., 1982). Esse lisímetro possui um sistema de abastecimento de água que mantém o nível do lençol freático constante no interior do reservatório no qual a cultura será semeada. A manutenção do nível do lençol freático permitirá o fornecimento de água para a zona radicular da cultura, pelo princípio da capilaridade, proporcionando uma condição potencial para a produção da cultura (MEDEIROS et al., 1998; MEDEIROS et al., 2001). Tais características tornam esse tipo de lisímetro uma técnica que promove a eficiência do uso da água pelas culturas (MEDEIROS et al., 2001).

O objetivo da presente pesquisa foi desenvolver e testar um protótipo voltado para o cultivo de hortaliças em residências e com potencialidade para a disseminação de conceitos relacionados à sustentabilidade da produção de alimentos e soberania alimentar.

\section{METODOLOGIA}

\section{Concepção e construção do protótipo de produção agrícola residencial}

A concepção adotada para a construção do protótipo correspondeu aquela do lisímetro de lençol freático de nível constante (ABOUKHALED et al., 1982). Assim, tem-se um sistema de produção agrícola eficiente no uso da água, já que a irrigação é subterrânea, reduzindo as perdas por evaporação e atendendo 
somente às necessidades de transpiração da cultura.

O lisímetro teve sua construção e teste hidráulicos realizados no Laboratório de Gestão e Recuperação de Áreas Degradadas da Universidade Estadual Paulista (Unesp), Campus de Sorocaba, no município de Sorocaba, estado de São Paulo, e teve as seguintes diretrizes para a sua concepção: a) Desenvolvimento de um protótipo que utilize de materiais disponíveis no comércio varejista; b) Desenvolvimento de um protótipo de produção agrícola que não demande energia elétrica sendo, portanto, viável para comunidades das mais distintas classes sociais e econômicas; c) Desenvolvimento de um protótipo que permita seu uso como módulo didático para a disseminação dos princípios da produção mais limpa, sustentabilidade e eficiência do uso da água; d) Desenvolvimento de um sistema baseado no princípio dos vasos comunicantes e eficiente no uso da água (MEDEIROS et al., 1998; MEDEIROS et al., 2001).

Dessa forma, o protótipo de produção agrícola residencial era constituído de três reservatórios comunicantes (Figura 1): a) Reservatório de alimentação: correspondeu a um barrilete de 20L, de PVC, com uma trena graduada para se determinar o nível de água no seu interior (Figura 2A); b) Reservatório de controle de fluxo: consistiu de um reservatório plástico de $29 \mathrm{~L}\left(0,149 \mathrm{~m}^{2}\right.$ de área da superfície), boia para caixa d'água $1 / 2$ ", para o controle do nível do lençol freático no interior do reservatório para o cultivo, e adaptador (Figura 2B); c) Reservatório para o cultivo: caixa plástica de $29 \mathrm{~L}\left(0,149 \mathrm{~m}^{2}\right.$ de área da superfície de superfície) e adaptador de caixa d'água.

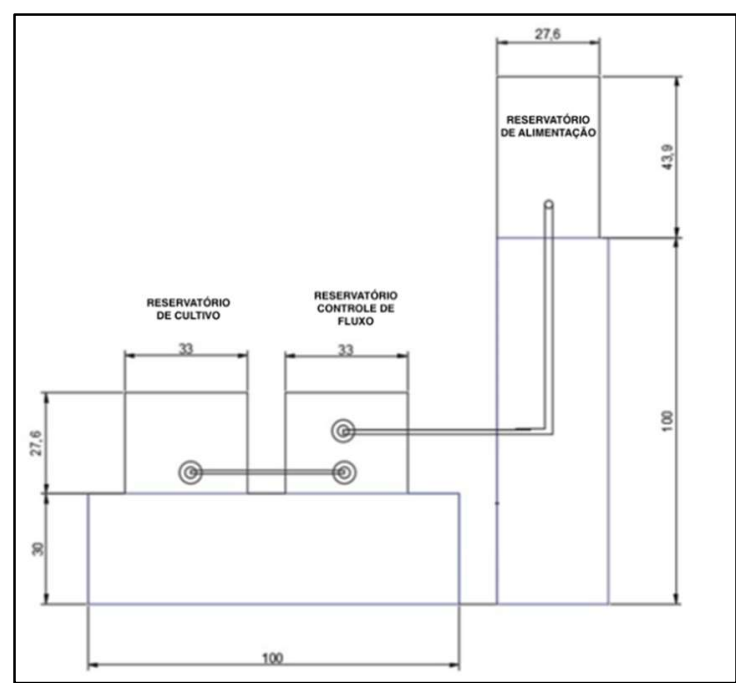

Figura 1: Vista lateral da estrutura do protótipo de produção agrícola residencial.
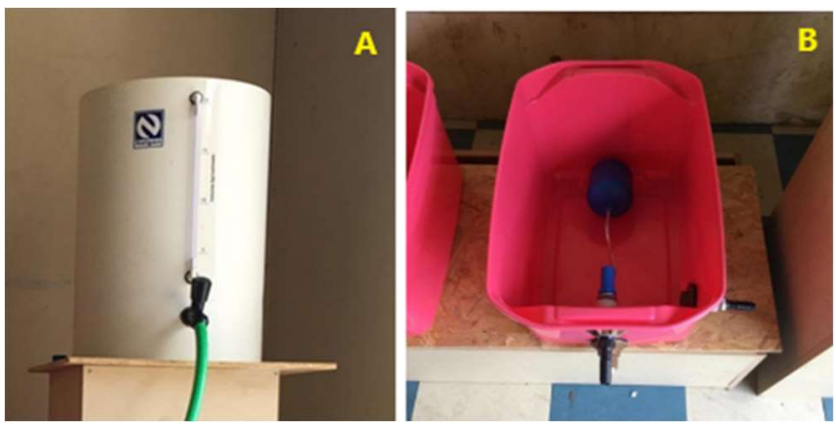

Figura 2: Detalhe do reservatório de alimentação $(A)$ e do reservatório de controle de fluxo (B) do protótipo de produção agrícola residencial.

Local e implantação dos ensaios conduzidos no protótipo de produção agrícola residencial

Local

Após a construção e testes hidráulicos, realizou-se uma avaliação do desempenho do protótipo de produção agrícola, por meio do cultivo da salsa (Petroselinum crispum) e espinafre (Tetragonia expansa) em uma residência localizada no Bairro Santa Rosália, na cidade de Sorocaba, estado de São Paulo.

Segundo a classificação de Köppen, em Sorocaba predominam o clima Cwa na depressão periférica e Cwb nas áreas mais elevadas, correspondendo ao tropical quente e úmido com inverno seco e verão 
chuvoso. No verão, a temperatura média é superior a $22^{\circ} \mathrm{C}$ e a pluviosidade média mensal atinge $200 \mathrm{~mm}$. Já no inverno a temperatura média é inferior a $18^{\circ} \mathrm{C}$ e a pluviometria média mensal alcança $30 \mathrm{~mm}$ (PIÑARODRIGUES et al., 2014). O protótipo foi instalado em área sombreada e parcialmente protegida da ação do vento (Figura 3).

A cultura foi semeada em terra vegetal, sem qualquer aplicação de pesticida ou adubo, em todos os ensaios realizados, sendo o fornecimento de água para as plantas unicamente realizado pelo sistema hidráulico do protótipo.

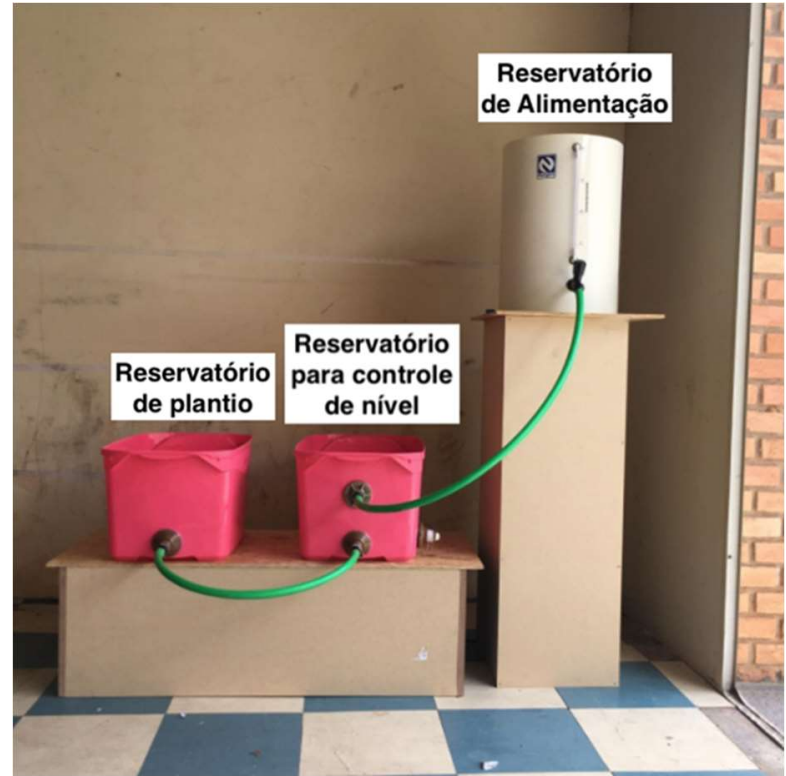

Figura 3: Estrutura do protótipo de produção agrícola instalado na residência em Sorocaba, estado de São Paulo.

Os dados meteorológicos levantados corresponderam à temperatura máxima, temperatura mínima e umidade relativa, obtidos diariamente no sítio de internet do Instituto Nacional de Meteorologia (INMET), correspondendo à estação meteorológica de código A713, localizada no município de Sorocaba.

\section{Culturas semeadas no protótipo de produção agrícola residencial}

A salsa (Petroselinum crispum), da família Apiaceae, é uma hortaliça com propriedades condimentares, sendo produzida e consumida em diversas regiões brasileiras, pois se adapta a uma faixa de temperatura variando de $15^{\circ} \mathrm{C}$ a $25^{\circ} \mathrm{C}$ (FILGUEIRA, 2013).

Devido a sua sensibilidade a altas temperaturas, telas de sombreamento são utilizadas para a redução da radiação solar incidente diretamente sobre a cultura (HOEPERS, 2017). Pela sua adaptabilidade às condições de sombreamento, a salsa foi selecionada para o cultivo residencial.

Essa planta demanda solos com boa drenabilidade, como os areno-argilosos, com alto teor de matéria orgânica, boa fertilidade e pH entre 5,8 e 6,8 para se atingir uma produtividade potencial, a qual pode variar de 500 a $1000 \mathrm{~kg} \mathrm{ha}^{-1}$. Sua primeira colheita é realizada entre 50 e 90 dias após a semeadura, quando as plantas atingem cerca de 15 a $20 \mathrm{~cm}$ de altura (HOEPERS, 2017).

O espinafre "Nova Zelândia" (Tetragonia expansa) pertence à família Aizoacea, sendo a espécie mais consumida no Brasil. Trata-se de uma planta rasteira, de textura semi-herbácea, cultivada para consumo in 
natura ou cozida (BIANCO, 2015). A planta pode atingir uma altura variando de 15 a $25 \mathrm{~cm}$, além de apresentar um ótimo desenvolvimento na faixa de temperatura de 15 a $20^{\circ} \mathrm{C}$ (FILGUEIRA, 2013). Portanto, a exemplo da salsa, apresenta um excelente potencial para cultivo em residências. Essa cultura se adapta melhor a solos férteis, frescos e úmidos, com boa drenagem e boa capacidade de retenção de água, sendo a sua colheita realizada quando as folhas atingem o tamanho desejado, entre 40 a 60 dias após o transplante (FILGUEIRA, 2013).

\section{Implantação dos experimentos preliminares para a avaliação do nível do lençol freático}

Três ensaios preliminares foram realizados para avaliar a influência do nível do lençol freático do sistema sobre o desempenho da cultura da salsa, semeada diretamente no módulo de produção agrícola, a partir de sementes adquiridas em estabelecimentos comerciais de produtos de jardinagem. 0 primeiro foi conduzido no período de 17 de novembro de 2019 a 19 de janeiro de 2020, quando o lençol freático foi mantido a 0,14 m de profundidade. 0 segundo correspondeu ao período de 19 de janeiro de 2020 a 10 de março de 2020, quando o lençol freático foi rebaixado a 0,17 m de profundidade.

O terceiro ensaio foi realizado no período de 11 de março de 2020 a 10 de abril de 2020, considerando uma profundidade de $0,20 \mathrm{~m}$ do lençol freático. O plantio seguiu o procedimento adotado nos ensaios anteriores, para essa cultura, ou seja, as sementes foram semeadas diretamente sobre a terra vegetal.

Implantação do experimento para a avaliação da eficiência do uso da água do protótipo de produção agrícola residencial

Esse ensaio foi desenvolvido no período 19 de maio a três de setembro, com a cultura do espinafre. Nesse experimento foram semeadas mudas dessa cultura, a uma densidade de plantio de 168 plantas. $\mathrm{m}^{-2}$, superior àquela observada em condições de campo, ou seja, 10 plantas.m-2 (BIANCO, 2015). Esse adensamento populacional teve por objetivo aumentar a produtividade e testar a capacidade do protótipo em fornecer água para a cultura, sob tais condições mesológicas.

Indicadores de desempenho no protótipo de produção agrícola residencial: crescimento da planta e matéria seca, consumo e eficiência do uso da água

\section{Parâmetros de desenvolvimento da planta e produção final}

Monitorou-se o crescimento do espinafre, por meio de método não destrutivo, tomando-se medidas de altura da planta acima da superfície do solo, ao longo do seu ciclo. A produção final (P) foi estimada a partir da colheita da parte aérea do espinafre, quando as amostras foram colocadas em estufa de secagem com circulação forçada de ar, a uma temperatura de $64^{\circ} \mathrm{C}$ por 24 horas (MEDEIROS et al., 2001).

\section{Eficiência do uso da água}

A eficiência do uso da água (EUA) é um indicador que integra aspectos relacionados ao meio ambiente, tecnologia, economia e agronomia, por isso tem potencial para ser utilizado nas análises da 
sustentabilidade na agricultura (MEDEIROS et al., 2014). Seu cálculo é feito pela seguinte fórmula (MEDEIROS et al., 2014):

$$
E U A=\frac{P}{E T}
$$

Em que EUA é a eficiência do uso da água $\left(\mathrm{kg} \cdot \mathrm{m}^{-3}\right) ; P$ a produção final de matéria seca $\left(\mathrm{g} \cdot \mathrm{m}^{-2}\right) ; E T$ a evapotranspiração acumulada da cultura $(\mathrm{mm})$

A evapotranspiração foi estimada diariamente, a partir da equação de balanço hídrico (MEDEIROS et al., 2001):

$$
\Delta A=(P+I+C)-(R+D+E T)
$$

Em que $\Delta A$ corresponde a variação de água armazenada na zona da raiz $(\mathrm{mm}), P$ a precipitação $(\mathrm{mm}), I$ a lâmina de irrigação aplicada superficialmente $(\mathrm{mm}), C$ o fluxo capilar ascendente para a zona da raiz desde o lençol freático $(\mathrm{mm}), R$ o escoamento superficial $(\mathrm{mm}), D$ a drenagem descendente para fora da zona da raiz $(\mathrm{mm}), E T$ a evapotranspiração da cultura $(\mathrm{mm})$

As condições de instalação do protótipo impediram a entrada de água por precipitação $(P)$ e a formação do escoamento superficial $(R)$, além de não ter sido aplicada a irrigação superficialmente $(I)$. $O$ tipo de lisímetro adotado permite desprezar a variação da água armazenada $(\Delta A)$, pois o solo permaneceu úmido ao longo de todo o ensaio, assim como a drenagem descendente $(D)$. Portanto, a evapotranspiração (ET) pôde ser calculada a partir do fluxo capilar ascendente para a zona da raiz desde o lençol freático $(C)$, o qual era medido diariamente, a partir da depleção da lâmina de água no interior do reservatório de alimentação (Figura 2A).

\section{RESULTADOS E DISCUSSÃO}

\section{Resultados dos experimentos preliminares para a avaliação do nível do lençol freático}

No primeiro experimento com a cultura da salsa, o lençol freático estava a 0,14 m de profundidade. Nesse ensaio, a salsa não recobriu o solo do protótipo de produção agrícola (Figura 4). A maior altura de planta atingiu $7 \mathrm{~cm}$, em 21/12/2019 (Figura 4C). Provavelmente, a profundidade do lençol freático afetou o crescimento da salsa, levando a uma aeração deficiente no sistema radicular. Por esse motivo, realizou-se um segundo experimento com a cultura da salsa (19 de janeiro a 10 de março de 2020), no qual o nível do lençol freático foi rebaixado para 0,17m. Antes do plantio retirou-se uma camada de 0,10 m de profundidade, trocando-a por nova terra vegetal (Figura 5).

Na Figura 5, pode-se visualizar que a salsa não apresentou um crescimento satisfatório, indicando que o solo persistia com elevada umidade. Assim, procedeu-se a um novo rebaixamento do lençol freático no terceiro ensaio (11 de março a 10 de abril de 2020), atingindo 0,20 m de profundidade, conforme recomendado por Klar et al. (2003) e Sandanielo et al. (2002), para hortaliças.

A Figura 6 permite visualizar a evolução da cobertura vegetal da salsa desde o seu plantio (Figura 6A) até a sua colheita (Figura $6 \mathrm{C}$ ). Observa-se um maior enfolhamento da cultura, em relação aos ensaios anteriores, provavelmente devido aos efeitos do rebaixamento do lençol freático.

Os resultados da produção final da salsa apresentaram uma matéria seca da parte aérea de 0,36 g e das raízes de 0,031 g. Considerando-se a área de plantio do protótipo de produção agrícola residencial $(0,149$ $\mathrm{m}^{2}$ ), essa produção corresponderia a $2,42 \mathrm{~g} \cdot \mathrm{m}^{2}$ ou $24,2 \mathrm{~kg} \cdot \mathrm{ha}^{-1}$. Esses valores foram bem inferiores aqueles 
observados por Hoeper (2017) para a salsa cultivada em ambiente sombreado, no Paraná. Todavia, nesse experimento a salsa foi inicialmente cultivada em bandejas e, posteriormente, transplantada.

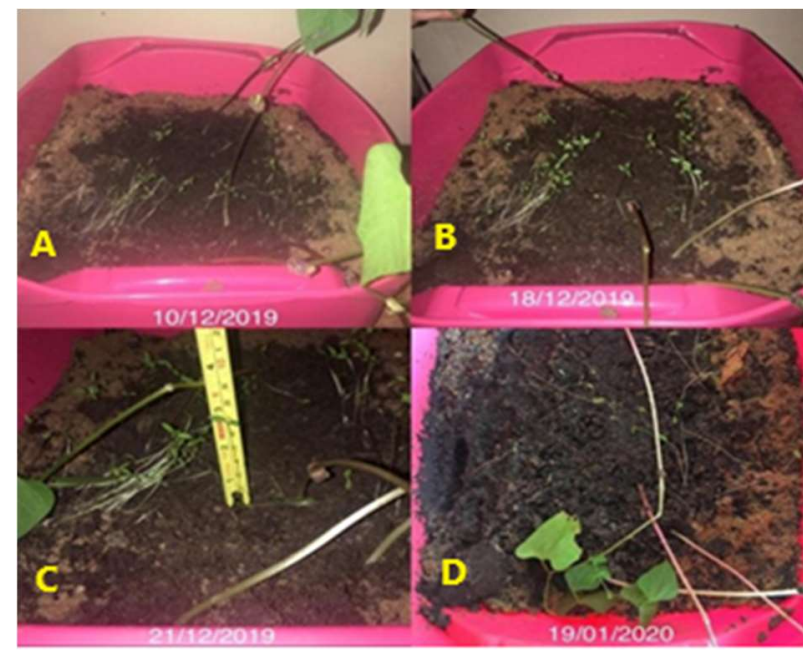

Figura 4: Desenvolvimento da cultura da salsa durante o experimento realizado no período de 17 de novembro de 2019 a 19 de janeiro de 2020, destacando o recobrimento do solo em quatro datas: (A) 10 de dezembro de 2019; (B) 18 de dezembro de 2019; (C) 21 de dezembro de 2019 e (D) 19 de janeiro de 2020, em Sorocaba - SP.

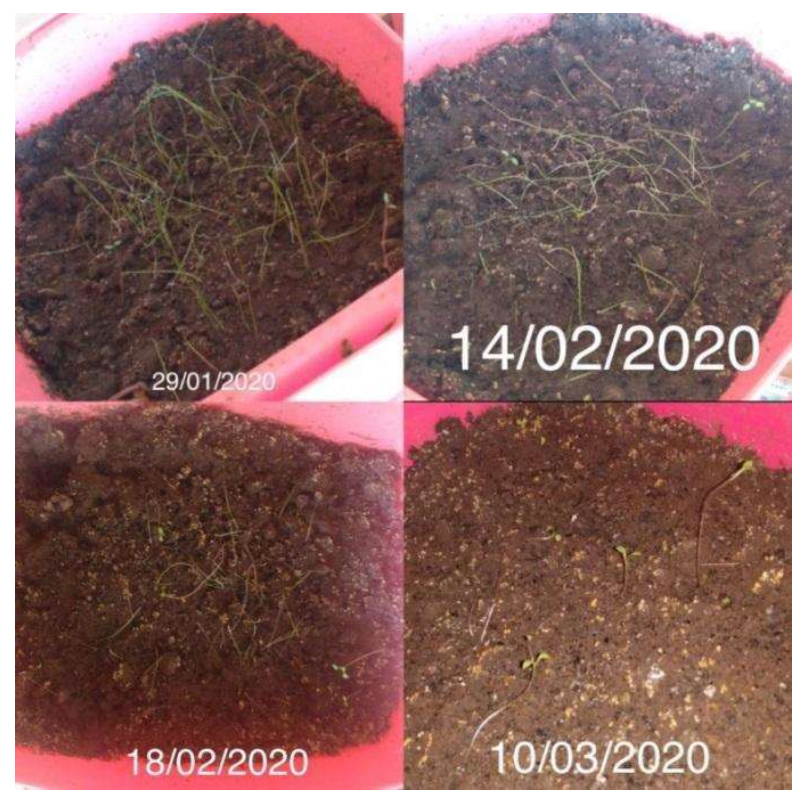

Figura 5: Desenvolvimento da cultura da salsa durante o experimento realizado no período de 19 de janeiro 10 de março, em Sorocaba, estado de São Paulo, em 2020.

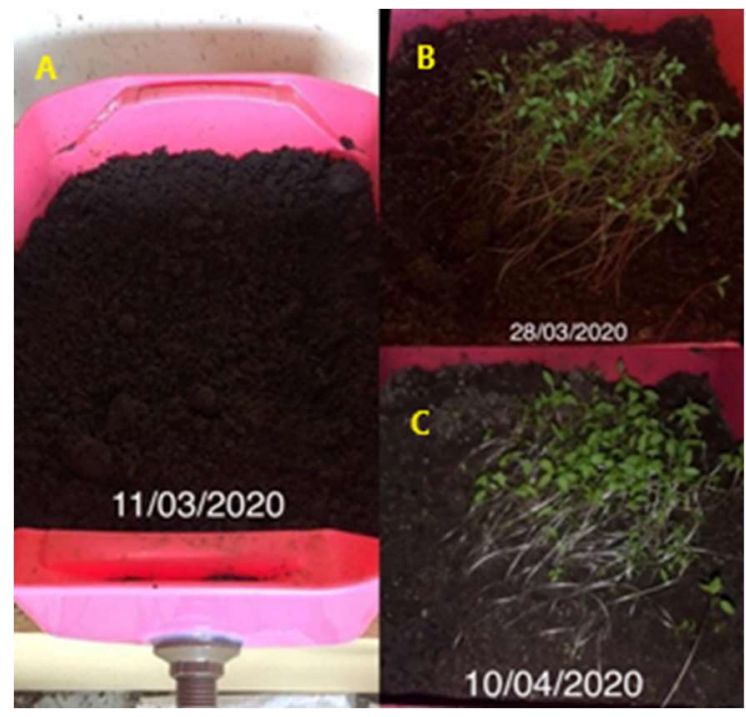

Figura 6: Cobertura vegetal da salsa desde o plantio $(A)$ até a sua colheita (C), em Sorocaba, estado de São Paulo, em 2020.

Tais resultados levaram a uma mudança na forma de conduzir o ensaio, optando-se pelo transplante de mudas de espinafre, ao invés de semeadura direta com sementes. Esse ensaio com o espinafre se iniciou em 19 de maio de 2020, estendendo-se até 3 de setembro de 2020. A seguir são descritas as condições climáticas desse ensaio, pois o consumo de água da cultura foi avaliado.

\section{Resultados do clima durante o ensaio do espinafre}

Na Figura 7 pode-se visualizar os parâmetros climáticos observados durante o ensaio com a cultura do espinafre (19 de maio a 3 de setembro de 2020). Nesse período, a temperatura média atingiu $18,9{ }^{\circ} \mathrm{C}$, 
sendo a média das temperaturas máximas de $25,4^{\circ} \mathrm{C}$ e a média das mínimas de $12,4{ }^{\circ} \mathrm{C}$. A umidade relativa, nesse período, alcançou um valor médio de 67,5\%. O período de 7 dias com o menor valor de umidade relativa foi de 8 a 14 de agosto, atingindo 50,1\%.

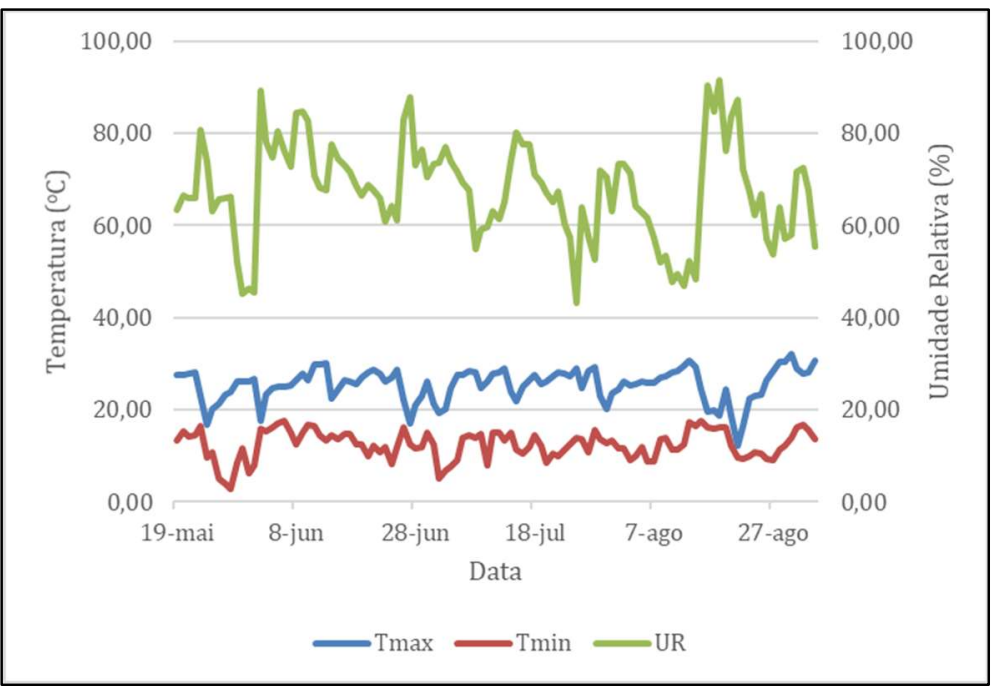

Figura 7: Parâmetros climáticos verificados durante o cultivo do espinafre no protótipo de produção agrícola residencial em Sorocaba-SP, no período de 19 de maio a 3 de setembro de 2020: temperatura máxima (Tmax), temperatura mínima (Tmin), e umidade relativa (UR),

\section{Resultados de planta do ensaio do espinafre}

O enfolhamento da cultura do espinafre, plantada no protótipo, pode ser visualizado ao longo do ciclo, desde a data do transplantio (Figura 8A) até a sua colheita (Figura 8D).

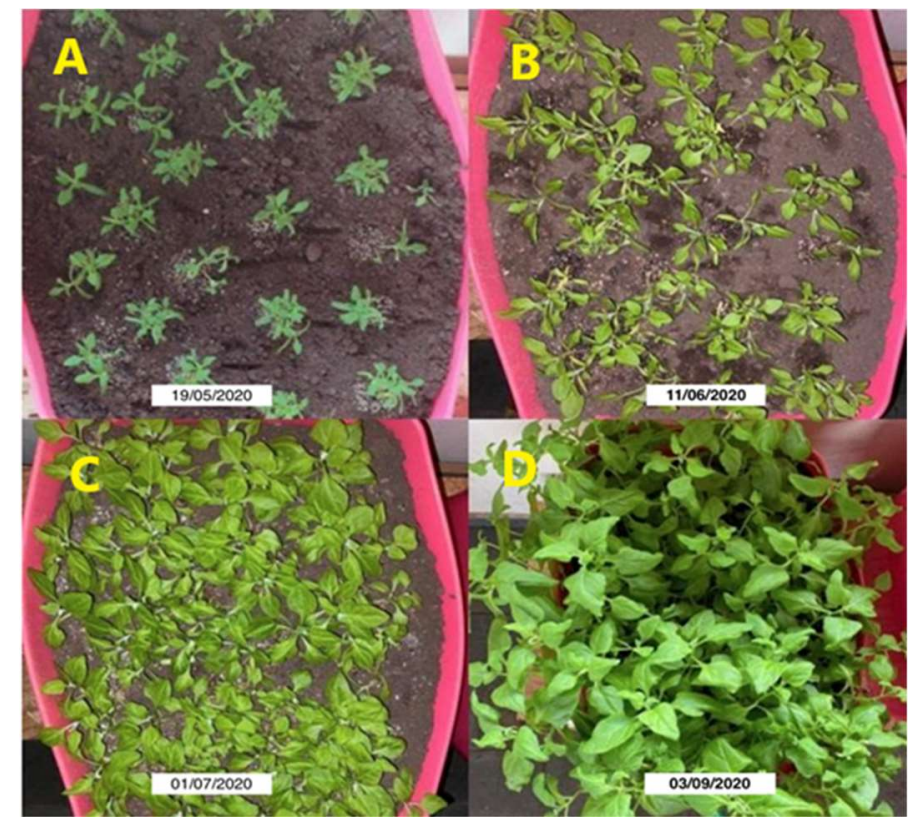

Figura 8: Evolução do crescimento da cultura do espinafre, transplantado para o reservatório de plantio do protótipo de produção agrícola residencial, em Sorocaba, estado de São Paulo, em 2020.

Observa-se que a cultura ultrapassou os limites do reservatório de plantio, um fenômeno observado em experimentos envolvendo lisímetros, pelas condições favoráveis de fornecimento de água (MEDEIROS et al., 2001). A evolução da altura da planta do espinafre pode ser visualizada na Tabela 1. O máximo valor medido, em 20 de agosto, está na faixa de variação esperada para a espécie de espinafre Nova Zelândia, de 
15 a $25 \mathrm{~cm}$ (BIANCO, 2015). Esse é um indicador do bom desempenho da cultura cultivada no protótipo proposto para produção agrícola residencial.

Tabela 1: Evolução da altura de planta do espinafre "Nova Zelândia" cultivado no protótipo de produção agrícola residencial, no município de Sorocaba, estado de São Paulo, em 2020.

\begin{tabular}{lllll}
\hline Data & 19 maio & 23 junho & 1 julho & 20 agosto \\
\hline Altura $(m)$ & 0,025 & 0,067 & 0,082 & 0,21 \\
\hline
\end{tabular}

A colheita do espinafre permitiu alcançar uma matéria seca total da parte aérea de $18,85 \mathrm{~g}$, ou 126,5 g. $\mathrm{m}^{-2}$, enquanto a matéria seca das raízes atingiu $1,03 \mathrm{~g}$, ou 6,9 g.m-2. Extrapolando tal resultado, essa produtividade corresponderia a 1.265,1 kg.ha-1. Não foram encontrados trabalhos na literatura de produção do espinafre Nova Zelândia com base na matéria seca. Todavia o aspecto visual no momento da colheita aponta para um bom desempenho da cultura, nas condições ambientais e de manejo do lençol freático do experimento (Figura 9).

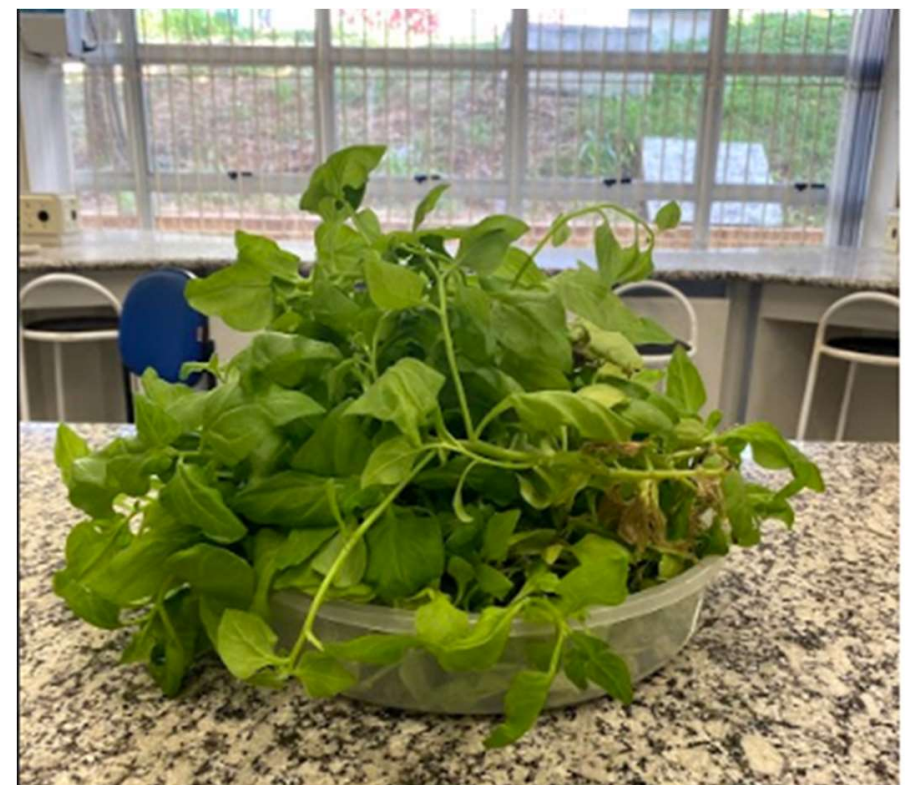

Figura 9: Aspecto visual do espinafre "Nova Zelândia" colhido no protótipo de produção agrícola residencial, em Sorocaba, estado de São Paulo, em 2020.

Deve-se acrescentar que não foi observada qualquer incidência de doença na cultura ao longo do ciclo, o que pode estar relacionado ao fornecimento de água por capilaridade, mantendo a superfície úmida, mas sem acúmulo de água, tampouco na folha. Esse resultado demonstra que o cultivo apresentou um comportamento alinhado com os princípios da produção orgânica, além de prevenir a geração de resíduos de embalagens de pesticidas e de fertilizantes químicos.

Portanto, baseado nos resultados desse experimento, a profundidade do lençol freático de $20 \mathrm{~cm}$ no protótipo de produção agrícola residencial permitiu boa produtividade do espinafre. 0 protótipo manteve seu desempenho mesmo sob adensamento populacional. Outra observação a ser destacada refere-se ao transplante de mudas preferencialmente à semeadura direta.

\section{Consumo e eficiência do uso da água do espinafre cultivado no protótipo de produção agrícola residencial}

A Figura 10 apresenta a variação do consumo de água da cultura do espinafre ao longo do ciclo, junto 
com a umidade relativa do ar.

O consumo acumulado da cultura do espinafre, ao longo de todo ciclo, atingiu $74 \mathrm{~mm}$, bem inferior ao observado para a brócolis cultivado em lisímetro de nível freático constante, em Botucatu-SP, o qual variou de 307 a 369 mm (KLAR et al., 2003). Uma causa para esse fenômeno pode ser o sombreamento da cultura e o impedimento parcial do fluxo de ar, em relação a uma cultura no campo.

No período de 27 de junho a 23 de julho o consumo de água da cultura, considerando uma média de sete dias, atingiu o máximo de 0,95 mm.dia ${ }^{-1}$, independente da variação na umidade relativa no período. Nessa época, a cultura estava com cerca de $80 \%$ de cobertura vegetal (Figura $8 \mathrm{C}$ ), quando para uma diversidade de culturas atinge-se uma demanda hídrica máxima (MEDEIROS et al., 2001; ALLEN et al., 1998). Após esse período, o consumo médio de água da cultura iniciou uma tendência de redução, provavelmente devido aos efeitos do adensamento populacional.

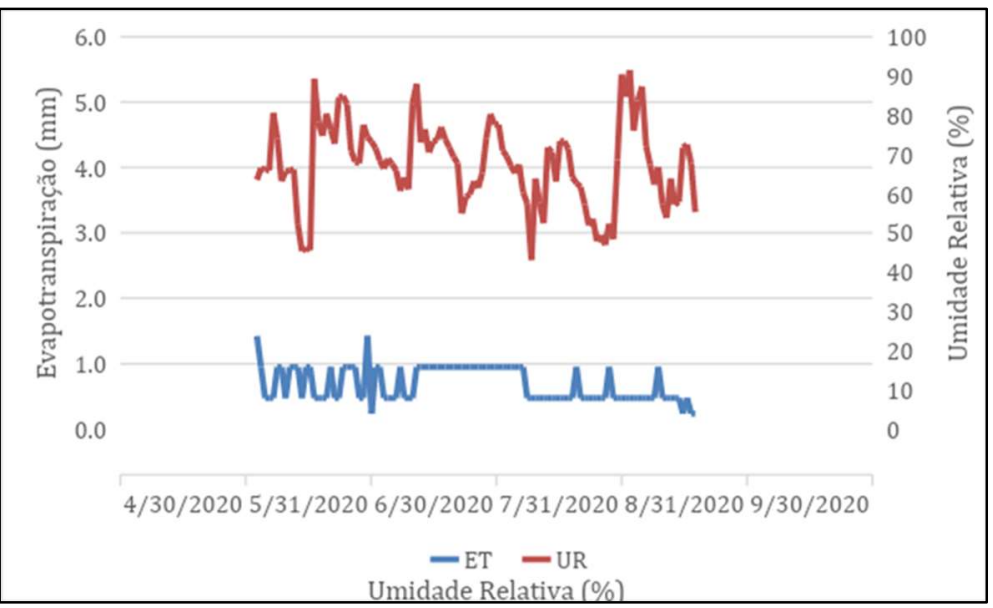

Figura 10: Evapotranspiração da cultura do espinafre (ET) e umidade relativa do ar (UR), durante o período do ensaio (19 de maio a 3 de setembro de 2020), em Sorocaba, estado de São Paulo.

Uma forma de manejo que poderia ser aplicado corresponderia ao desbaste da cultura, pois por volta de 60 dias após o transplante já se pode iniciar a colheita (BIANCO, 2015). Apesar do efeito do adensamento populacional, a eficiência do uso da água atingiu $0,25 \mathrm{~kg} \cdot \mathrm{m}^{-3}$, ou 17,10 t.ha-1. $\mathrm{mm}^{-1}$ um valor que pode ser considerado elevado quando comparado a outras hortaliças irrigadas, como pepino $\left(0,262 \mathrm{t}\right.$.ha $\left.\mathrm{ham}^{-1} \cdot \mathrm{mm}^{-1}\right)$ (YAGHI et al., 2013) ou brócolis $\left(0,014\right.$ t.ha $\left.{ }^{-1} \cdot \mathrm{mm}^{-1}\right)$ (KLAR et al., 2003).

\section{CONCLUSÕES}

A simplicidade construtiva e operacional, a independência do suprimento de energia e o desempenho da cultura do espinafre transplantado, demonstraram que o protótipo de produção agrícola concebido e testado foi adequado para o uso em residências, contribuindo para o planejamento do uso de recursos naturais voltados a promover a soberania e segurança alimentar no meio urbano. Pesquisas relacionadas às formas de manejo da cultura necessitam ser realizadas, todavia os resultados obtidos apontaram para a eficiência do uso da água e melhores condições fitossanitárias do espinafre cultivado em ambiente residencial, em relação a uma cultura manejada no campo. 
AGRADECIMENTOS: Ao Conselho Nacional de Pesquisa (CNPQ).

\section{REFERÊNCIAS}

ABOUKHALED, A.; ALFARO, A.; SMITH, M.. Lysimeters. Rome: FAO, 1982.

ALBERS, C. N.; JACOBSEN, O. S.; BESTER, K.; JACOBSEN, C. S.; CARVALHO, P. N.. Leaching of herbicidal residues from gravel surfaces: a lysimeter-based study comparing gravels with agricultural topsoil. Environmental Pollution, v.266, n.115225, 2020. DOI: http://doi.org/10.1016/i.envpol.2020.115225

ALLEN, R. G.; PEREIRA; L. S.; RAES, D.; SMITH, M.. Crop evapotranspiration: guidelines for computing crop water requirements. Rome: FAO, 1998.

ANDRADE, T. A.; SERRA, R. V.. Cidades médias brasileiras. Rio de Janeiro: IPEA, 2001.

BENIS, K.; FERRÃO, P.. Potential mitigation of the environmental impacts of food systems through urban and peri-urban agriculture (UPA) e a life cycle assessment approach. Journal of Cleaner Production, v.140, p.784-795, 2017. DOI: http://dx.doi.org/10.1016/j.jclepro.2016.05.176

BIANCO, M. S.. Viabilidade agroeconômica do consórcio de couve com espinafre 'Nova Zelândia'. Tese (Doutorado em Agronomia) - Universidade Estadual Paulista, Jaboticabal, São Paulo, 2015.

BRANCO, M. C.; LIZ RS; ALCÂNTARA, F. A.; MARTINS, H. A. G.; HANSON, J. C.. Agricultura apoiada pela comunidade: poderia a experiência dos agricultores americanos ser útil para os agricultores urbanos brasileiros?. Horticultura Brasileira, v.29, n.1, p.43-49, 2011. DOI: http://doi.org/10.1590/S0102-05362011000100008

BOLANG, P. D.; OSUMANU, I. K.. Formal sector workers' participation in urban agriculture in Ghana: perspectives from the Wa Municipality. Heliyon, v.5, n.e02230, 2019. DOI: http://doi.org/10.1016/i.heliyon.2019.e02230

CARVALHO, I. V.; BRANDUINI, P. N.. Patrimonio y agricultura urbana en Recife: análisis y directrices para el barrio de várzea. Revista Urbano, v.36, p.30-41, 2017.

COSTA, M. P.; SCHOENEBOOM, J. C.; OLIVEIRA, S. A.; VIÑAS, R. S.; MEDEIROS, G. A.. A socio-eco-efficiency analysis of integrated and non-integrated crop-livestock-forestry systems in the Brazilian Cerrado based on LCA. Journal of Cleaner Production, v.140, p.1460-1471, 2018. DOI: http://doi.org/10.1016/j.jclepro.2017.10.063

DEELSTRA, T.; GIRARDET, H.. Urban agriculture and sustainable cities. In: BAKKER, N.; DUBBELING, M.; GÜNDEL, S.; SABEL-KOSCHELLA, U.; ZEEUW, H.. Growing cities, growing food: urban agriculture on the policy agenda. Feldafing: Deutsche Sitffung für Internationale Entwicklung, 2000. p.43-65.

DIELEMAN, H.. Urban agriculture in Mexico City; balancing between ecological, economic, social and symbolic value. Journal of Cleaner Production, v.163, p.S156-S163, 2017. DOI: http://dx.doi.org/10.1016/i.jclepro.2016.01.082
EEA. European Environment Agency. Environmental Indicators Report 2018. Luxembourg: Publications Office of the European Union, 2018.

FEOLA, G.; SUZUNAGA, J.; SOLER, J.; WILSON, A.. Peri-urban agriculture as quiet sustainability: Challenging the urban development discourse in Sogamoso, Colombia. Journal of Rural Studies, v.79, 2020. DOI: http://doi.org/10.1016/j.jrurstud.2020.04.032

FILGUEIRA, F. A. R.. Novo manual de olericultura: agrotecnologia moderna na produção e comercialização de hortaliças. Viçosa: UFV, 2013.

HALL, G.; ROTHWELL, A.; GRANT, T.; ISAACS, B.; FORD, L.; DIXON, J.; KIRK, M.; FRIEL, S.. Potential environmental and population health impacts of local urban food systems under climate change: a life cycle analysis case study of lettuce and chicken. Agriculture \& Food Security, v.3, n.6, p.1-13, 2014.

HE, C.; LIU, Z., XU, M.; MA, Q.; DOU, Y.. Urban expansion brought stress to food security in China: evidence from decreased cropland net primary productivity. Science of the Total Environment, v. 576, p.660-670, 2017. DOI: http://dx.doi.org/10.1016/i.scitotenv.2016.10.107

HOEPERS, L. M. L.. Crescimento de cultivares de salsa (Petroselinum crispum) em condições de sombreamento e a pleno Sol. Dissertação (Mestrado em Agronomia) Universidade Estadual do Oeste do Paraná, Marechal Cândido Rondon, 2017.

KLAR, A. E.; FONTES, E. W. S.. Water use by broccoli plants (Brassica oleracea F, var. Italica). Irriga, Botucatu, v.8, n.1, p.37-43, 2003. DOI:

http://doi.org/10.15809/irriga.2003v8n1p37-43

MADALENO, I. M.. Plantas da medicina popular de São Luís, Brasil. Boletim do Museu Paraense Emílio Goeldi. Ciências Humanas, v.6, n. 2, p.273-286, 2011.

MADALENO, I. M.. Urban agriculture in Belém, Brazil. Cities, v.17, n.1, p.73-77, 2000. DOI: http://doi.org/10.1016/S02642751(99)00053-0

MARQUES, B. V. M.; PECHE FILHO, A.; MEDEIROS, G. A.; FERNANDES, B. V. M.; LIGOSKI, G. R.. Índice de desempenho tecnológico: uma ferramenta para o planejamento e gestão de propriedades rurais no cerrado brasileiro. Brazilian Journal of Animal and Environmental Research, Curitiba, v.3, n.1, p.9-22, 2020.

MEDEIROS, G. A.; ARRUDA, F. B.; RIBEIRO, A. I.. Water use efficiency as an indicator of environmental impact of irrigated crops under subtropical conditions. WIT Transactions on Ecology and The Environment, v.181, p.455-463, 2014. DOI: http://dx.doi.org/10.2495/EID140391

MEDEIROS, G. A.; ARRUDA, F. B.; SAKAI, E.. Crop coefficient for irrigated beans derived using three reference evaporation methods. Agricultural and Forest Meteorology, 
v.135, p.135-143, 2005. DOI:

http://doi.org/10.1016/i.agrformet.2005.11.010

MEDEIROS, G. A.; ARRUDA, F. B.; SAKAI, E.; FUJIWARA, M.. The influence of crop canopy on evapotranspiration and crop coefficient of beans (Phaseolus vulgaris L.). Agricultural Water Management, v.49, n.3, p.211-224, 2001. DOI: http://doi.org/10.1016/S0378-3774(00)00150-5

MEDEIROS, G. A.; ARRUDA, F. B.. Adaptação e avaliação de evapotranspirômetros para a obtenção do coeficiente de cultura basal (kcb) do feijoeiro (Phaseolus vulgaris L.). Irriga, Botucatu, v.4, n.2, p.92-103, 1998. DOI:

http://dx.doi.org/10.15809/irriga.1998v03n3p73-80

PIÑA-RODRIGUES, F. C. M.; AOKI, J.. Chuva de sementes como indicadora do estádio de conservação de fragmentos florestais em Sorocaba, SP. Ciência Florestal, Santa Maria, v.24, n.4, p.911-923, 2014. DOI:

http://dx.doi.org/10.5902/1980509816603

RIBEIRO, S. M.; BÓGUS, C. M.; WATANABE, H. A. W.. Agricultura urbana agroecológica na perspectiva da promoção da saúde. Saúde e Sociedade, v.24, n.2, p.730-
743, 2015. DOI: http://dx.doi.org/10.1590/S010412902015000200026

SANDANIELO, A.; LUNARDI, D. M. C.. Coeficientes de cultura da chicória (Cichorium endiva L.). Irriga, v.7, n.2, p.76-80, 2002. DOI: http://doi.org/10.15809/irriga.2002v7n2p65-80

ULM, F.; AVELAR, D.; HOBSON, P.; PENHA-LOPES, G.; DIAS, T.; MÁGUAS, C.; CRUZ, C.. Sustainable urban agriculture using compost and an open-pollinated maize variety. Journal of Cleaner Production, v.212, p.622-629, 2019. DOI: http://doi.org/10.1016/i.jclepro.2018.12.069

WIELEMAKER, R.; OENEMA, O.; ZEEMAN, G.; WEIJMA, J. . Fertile cities: Nutrient management practices in urban agriculture. Science of the Total Environment, v.668, p.1277-1288, 2019. DOI: http://doi.org/10.1016/i.scitotenv.2019.02.424

YAGHI, T.; ARSLAN, A.; NAOUM, F.. Cucumber (Cucumis sativus, L.) water use efficiency (WUE) under plastic mulch and drip irrigation. Agricultural Water Management, v.128, p.149-157, 2013. DOI: http://doi.org/10.1016/j.agwat.2013.06.002

A CBPC - Companhia Brasileira de Produção Científica (CNPJ: 11.221.422/0001-03) detém os direitos materiais desta publicação. Os direitos referem-se à publicação do trabalho em qualquer parte do mundo, incluindo os direitos às renovações, expansões e disseminações da contribuição, bem como outros direitos subsidiários. Todos os trabalhos publicados eletronicamente poderão posteriormente ser publicados em coletâneas impressas sob coordenação da Sustenere Publishing, da Companhia Brasileira de Produção Científica e seus parceiros autorizados. Os (as) autores (as) preservam os direitos autorais, mas não têm permissão para a publicação da contribuição em outro meio, impresso ou digital, em português ou em tradução. 